\title{
The Search for Biomarine-derived Compounds with Immunomodulatory Activity
}

\author{
Valter R.M. Lombardi ${ }^{*}$, Lola Corzo ${ }^{2}$, Iván Carrera ${ }^{1}$ and Ramón Cacabelos ${ }^{2}$ \\ ${ }^{1}$ Department of Health Biotechnology, Euroespes Biotechnology, Corunna, Spain; ${ }^{2}$ Institute for CNS Disorders and Genomic Medicine, \\ EuroEspes Biomedical Research Center, Bergondo, Corunna, Spain
}

\begin{abstract}
Many clinical conditions exist in which it is desirable to stimulate or suppress the immune system, and many different drugs are able to do this. It is also well known that nutrition may affect human health and immune responses. Nutritional factors are crucial components of the diet, essential for the normal growth and development of both vertebrate and invertebrate organisms. Many of these components have been shown to play different roles in the immune response, and under different circumstances they can significantly modulate the immune system to create an effective response. The aim of the present review was to show the effect of a biomarine lipofishin (E-JUR-94013) obtained from the species T. trachurus, present on the Galician coast of the Atlantic Ocean, in the improvement of immune system function. In humans, the results obtained under different clinical conditions clearly demonstrated the ability of E-JUR-94013 to improve the host innate and acquired immune responses. In three different clinical studies, 56, 205 and 1,500 patients were included, respectively. All patients were supplemented with $750 \mathrm{mg} /$ day of E-JUR-94013. In the first study, significant increases in $\operatorname{lgA}(p=0.033)$ and IgG $(p=0.016)$, and a reduction in IgE were observed. In the second study, a normalization in leukocyte cell counts after treatment was observed $(p<0.05)$. The main objective of the last study was to correlate inflammatory genotypes with response to E-JUR-94013. The results obtained indicated that high ultrasensitive C-reactive protein was down-regulated. In addition, both IL-6-C573G and IL16-T3954C genotypes clearly correlated with response to E-JUR-94013 treatment. Taken together, these results suggest that supplementation of diets with EJUR-94013 can be employed to improve, enhance and regulate certain immune responses and lead to increased resistance to disease.
\end{abstract}

Pharmacological potential of marine metabolites

The oceans cover more than $70 \%$ of the earth's surface and contain over 300,000 described species of plants and animals. ${ }^{1}$ Macroscopic plants and animals have adapted to all regions of the oceans, including polar, temperate and tropical areas. The diversity in species is extraordinarily rich on coral reefs, where there are around 1,000 species per $\mathrm{m}^{2}$ in some areas, and the Indo-Pacific Ocean has the world's greatest tropical marine biodiversity. ${ }^{2}$ The

Keywords: Lipofishins; Immunomodulation; Dietary supplements; E-JUR-94013. Abbreviations: AMP, antimicrobial peptide; ET-743, ecteinascidin 743; us-CRP, ultrasensitive C-reactive protein.

Received: December 20, 2017; Revised: January 25, 2018; Accepted: January 29, 2018

${ }^{*}$ Correspondence to: Valter R.M. Lombardi, Euroespes Biotechnology, Department of Health Biotechnology, Polígono Industrial de Bergondo, C/. Parroquia de Guísamo s/n, Parcela A6 NaveF 15166 Bergondo, Corunna, Spain. Tel: +34 981 784848; Fax: +34981 784845; E-mail: biotecnologiasalud2@ebiotec.com

How to cite this article: Lombardi VRM, Corzo L, Carrera I, Cacabelos R. The Search for Biomarine-derived Compounds with Immunomodulatory Activity. $J$ Explor Res Pharmacol 2018;3(1):30-41. doi: 10.14218/JERP.2018.00006. first result of such a high level of biodiversity is the great number of different kinds of interactions involving different organisms. In addition to trophic relationships, of particular importance are the so-called co-evolutive relationships, such as epibiosis, commensalism, mutualism and parasitism. While free movers, such as fish and crustaceans, interact with each other through the movement of appendices, hearts or tentacles, sessile organisms mainly interact via the production of secondary metabolites, which can also have important applications for humans (e.g., some of these exhibit strong biological activities). In this way it is possible to state that the number and activity of natural products is directly related to the level of biodiversity of a marine area.

Nature represents an endless arsenal of new bioactive molecules and the study of these metabolites has historically proven to be of immense benefit in the drug discovery process. ${ }^{3}$ The history of terrestrial natural product chemistry can readily be traced back to the beginning of the $19^{\text {th }}$ century, with the first research on terrestrial plants aimed at finding the molecules responsible for the biological activities of the extracts.

The marine environment has proven to be a highly rich source of extremely potent compounds that have demonstrated significant activities in antitumor, antiinflammatory, analgesic, immunomodu- 
latory, antiallergic and antiviral assays. ${ }^{4}$ To date, more than 25,000 marine natural products have been isolated from 3,000 marine organisms, and reported in about 8,000 publications (these data refer to early 2009). Bioactive products have been isolated from animalia and plantae, as well as from marine microorganisms such as bacteria and fungi, protozoa and chromista.

These natural products or secondary metabolites, which are supposed to be the result of evolutionary pressures such as predation or competition for space and resources, have been transformed into structurally diverse and mostly stereochemically complex compounds, many of which belong to novel chemical groups not found in terrestrial organisms, possessing specific and pronounced biological activity. Although the biogenetic origin of this plethora of marine secondary metabolites can be conceived in the realm of the biosynthetic pathways commonly proposed for their terrestrial counterparts, they often integrate uniquely or predominantly marine functional groups in their structures. As an illustrative example we can cite the abundance of halogenated compounds, most likely as a consequence of the relative abundance of halogen atoms in the marine environment, but also of functional groups such as isonitrile, thiocyanate, sulfamate and formamide, which are much more abundant among marine metabolites than among those terrestrial. ${ }^{5,6}$

In short, simple natural organisms, such as marine invertebrates, are able to create new structures in a multitude of different ways, and natural products thus constitute a potentially infinite source of molecular diversity, unmatched by any synthetic chemical collection or combinatorial chemistry. However, it should be acknowledged that the finding of new bioactive natural molecules, called "lead compounds" represents only a starting point in the drug discovery process. This step must indeed be followed by an in-depth investigation of the biological potential of the molecule and of the molecular interactions between the molecule and its target.

The most interesting and promising marine natural products are small- to medium-size molecular weight compounds produced principally by marine invertebrates (sponges, tunicates, soft corals) and microbes that have spurred interdisciplinary studies by chemists, ${ }^{7-10}$ biologists and pharmacologists. The incredible potential of even a single marine organism to produce a wide array of secondary metabolites can be interpreted by considering the common features of secondary metabolism in all the living organisms as well as some peculiar features of the marine environment. Secondary metabolites play an essential role in the adaptation of the producer organism to the environment, mainly, but not uniquely, in terms of defense; they are practically the sole tool in the hands of organisms at lower evolutionary levels or lacking mechanical or morphological ways of protecting themselves (this is the case of sessile organisms such as plants and algae, and marine invertebrates such as sponges, tunicates and bryozoans). Since the production of secondary metabolites has been selected by these organisms as a strategy for their survival, and since potent biological activity must be considered to be a rare molecular property, the greater the number of secondary metabolites produced by an organism, the more chances it has to be winning in the evolutionary competition.

It is now generally accepted that metabolic pathways of the secondary metabolism are intrinsically different from those characterizing the primary metabolism. Two main differences, the consequence of being a wider chemodiversity at low cost, can be recognized: i) enzymes of secondary metabolism generally have a broader substrate tolerance and thus the same enzyme can be used to produce different products or, alternatively, the same product can be produced by more than one route; ii) biosynthesis of sec- ondary metabolites is characterized by the possibility of producing more than one end-product. This goal is reached at low cost by using enzymes that possess the ability to create and manage unstable intermediates (such as carbocations or radicals) that are able to result in the formation of a variety of stable products. A further variability is reached with the incorporation of non-enzyme reactions in the metabolic pathways.

With regard to marine invertebrates, in addition to these two points, the extremely rich secondary metabolism could also be interpreted in the light of the possible contribution of the symbiotic population to the metabolic work. Indeed, marine invertebrates harbor in their tissues, in the extra- and intracellular spaces, a series of microorganisms such as bacteria, cyanobacteria and fungi. In some cases, associated microorganisms may constitute up to $40 \%$ of the biomass, this bacterial concentration exceeding that of the surrounding sea water by two or three orders of magnitude. For example, according to recent studies, ${ }^{11,12}$ sponges can be regarded as "microbiological fermenters" containing novel species-specific marine microorganisms. Although the real contribution of the microorganisms to the secondary metabolism of marine invertebrates has not yet been fully understood and evaluated, essentially because of the difficulties encountered in culturing sponge-associated bacteria, it is generally accepted that these harbored microorganisms play a significant role in the biosynthesis of the natural products isolated from the invertebrate.

For all the reasons summarized above, it is not surprising that chemical analysis of a single marine invertebrate, performed with nondestructive modern spectroscopic techniques (enabling the stereostructure elucidation of molecules isolated in the low milligram range) can afford tens, when not hundreds, of secondary metabolites. These products provide a rich source of chemical diversity that can be fruitfully used as a "natural combinatorial library," frequently richer and more chemically diverse than the libraries obtained through the use of synthetic combinatorial chemistry. Ideally, this "natural library" can be screened in order to find lead compounds to be used as inspiration to design and develop new potentially useful therapeutic agents and to obtain the first information about structure-activity relationships.

In spite of the difficulties associated with the limited availability of the compounds under investigation, which is strictly related to the limited supply of the biological material duly protected for environmental reasons, some interesting results have been obtained. Through the combined efforts of marine natural product chemists and pharmacologists, an astounding array of promising compounds have been identified. Some of these molecules are either at advanced stages of clinical trials or have been selected as promising candidates for extended pre-clinical evaluation. The majority of these products fall within the area of antimicrobial and cancer therapies. To cite an example, ecteinascidin 743 (ET-743), an antitumor compound that is particularly effective against solid tumors, has entered the drug market in Europe. ${ }^{13}$

Luckily, two recent trends in marine science also promise to overcome the problem of compound supply: i) the increasing progress in marine culture; and, ii) the recent impressive advances in molecular genetics, currently enabling the identification of biosynthetic clusters in the producer organisms and their cloning in bacteria suitable for large-scale fermentation. If these techniques were fully developed and utilized, the final obstacle to considering marine organisms as a potentially sustainable drug source would be overcome. Thus, hopefully, in the near future, the incredible chemical diversity of the secondary metabolites produced by marine invertebrates will be utilized in full, and the great marine potential will become a brilliant reality of medicinal chemistry. 


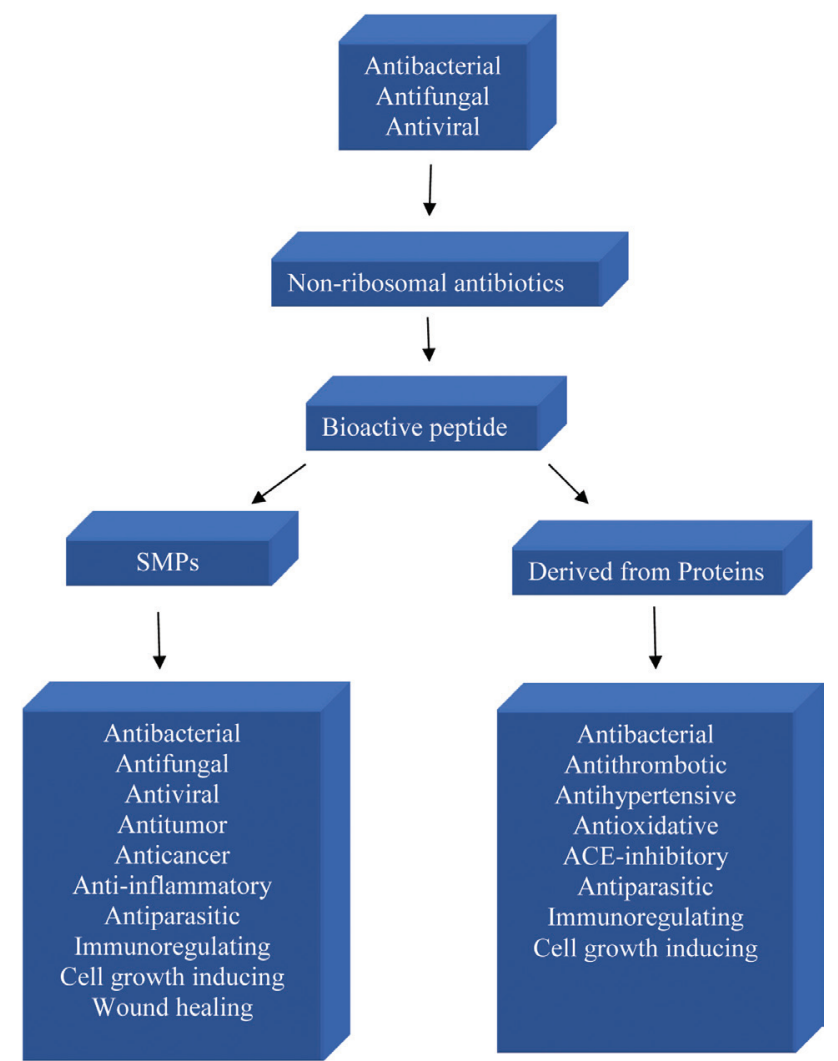

Fig. 1. Different types of small bioactive peptides and their activities.

Fatty acids, small marine peptides and the immune system

It is well known that correct nutrition is essential for the maintenance of normal growth of all vertebrates, including mammals. In addition, nutritional factors play important roles in the immune response. Vitamins A, B6, C and E as well as the minerals iron, selenium, zinc and fluoride have been identified as micronutrients that can affect disease resistance. ${ }^{14}$

During the past three decades, increased attention has been focused on different naturally-derived compounds capable of modulating the immune system by increasing the host's resistance in order to reduce susceptibility to infections and various diseases involving the immune system. ${ }^{15,16}$ The immune system is our shield against disease. Due to its complexity, it is difficult to assess the effects of diet on our immune function. However, different studies have demonstrated that dietary habits may affect the human immune response. Over the past 10 years, nutrition has been shown to play a major role in supporting the production and action of both the cells and the soluble factors of the immune system. ${ }^{17,18}$ Proteins, antioxidants, essential fatty acids, certain vitamins, and minerals have been shown to be essential factors for a healthy immune system. The biological effects of immunostimulants are highly dependent on the receptors on the target cells, recognizing them as potential high-risk molecules, as they can trigger various defense pathways.

Among various species, fish meal is recognized as a rich source of digestible protein with a high content of amino acids, vitamins and minerals. Diet supplementation with oily fish, rich in docosahexaenoic and eicosapentaenoic omega-3 fatty acids, is a wellknown strategy to modify the human immune response. ${ }^{19-21}$ Ani- mal and human molecular studies have shown that fish oil feeding results in suppressed production of proinflammatory cytokines and can decrease adhesion molecule expression. These effects occur at the level of altered gene expression.

Dietary bluefish oil has been found to ameliorate the symptoms of chronic inflammatory disease in some animal models and to protect against the effects of endotoxins and similar inflammatory challenges. ${ }^{19}$ Cave et al..$^{22}$ reported that inflammatory problems at the molecular level in obese patients may be corrected by a number of dietary agents, such as arginine, fish oil and carnitine. Furthermore, several epidemiological, experimental and randomized controlled studies supported the effects of oily fish intake in the prevention of breast cancer cell metastasis to bone, ${ }^{23}$ atherosclerosis and vascular diseases, ${ }^{24,25}$ inflammatory bowel disease and rheumatoid arthritis, ${ }^{26}$ among others.

Besides possessing nutritional value, peptides have several important functions in various organisms: antibacterial, antifungal, antiparasitic, antiviral, antitumor, antioxidative, antihypertensive, antiinflammatory, immunoregulating, cell growth inducing, hormone signaling and health activities (Fig. 1). Peptides with antimicrobial activity provide defense against invasive pathogens and have excellent properties to kill many common antibiotic-resistant bacterial strains. ${ }^{27-29}$ Antimicrobial peptides (AMPs) are generally considered an important part of the innate (nonadaptive) immune defense system.

AMPs are encoded by AMP genes and produced ribosomally, mainly as prepropeptides. Host-defense AMPs are produced in specialized immune-competent cells by all living organisms, including bacteria, fungi, plants, invertebrates and vertebrates. Roughly 2,400 peptide sequences with antimicrobial activity have been described to date. ${ }^{30}$ In addition, some bioactive peptides are encoded within protein sequences with no obvious antimicrobial or other specific function. These peptides are either released during food processing, enzymatic degradation or gastrointestinal digestion. ${ }^{31,32}$ Some peptides with antibiotic properties, such as vancomycin and surfactin, are produced by bacteria and fungi using nonribosomal peptide synthetases. ${ }^{33,34}$

AMPs are relatively small molecules that typically possess a net positive charge and rapidly bind to bacterial membranes, form pores and kill bacteria. ${ }^{35-37}$ Host defense AMPs work to enhance host organism immune systems. ${ }^{38,39}$ They are able to stimulate the expression of cytokines, which, in turn, control the subsequent immune response. ${ }^{40}$ Furthermore, some AMPs play an antiinflammatory role by blocking the inflammatory response and septic shock in host organisms. ${ }^{41}$

\section{Benefits of E-JUR-94013}

E-JUR-94013 (DefenVid $®$; Ebiotec, A Coruña, Spain) is a lipofishin derived from the species Trachurus trachurus, with antiinflammatory activity and powerful immune-enhancing properties in cases of immunodeficiency, microbial infections and/or diseases in which there is a functional compromise of the immune system. According to in vitro and in vivo studies, ${ }^{42-44}$ the results showed a stimulation of antibody-secreting cell response, enhancement of phagocytosis, modification/enhancement of cytokine production and improvement of the host-acquired immune responses.

E-JUR-94013 is a food supplement lipoprotein obtained from the T. trachurus fish on the Galician coast of the Atlantic Ocean. This lipoprotein extract is a $100 \%$ natural compound, produced by mechanical transformation and lyophilization processes, which preserve the nutritional and biological properties of the species. 

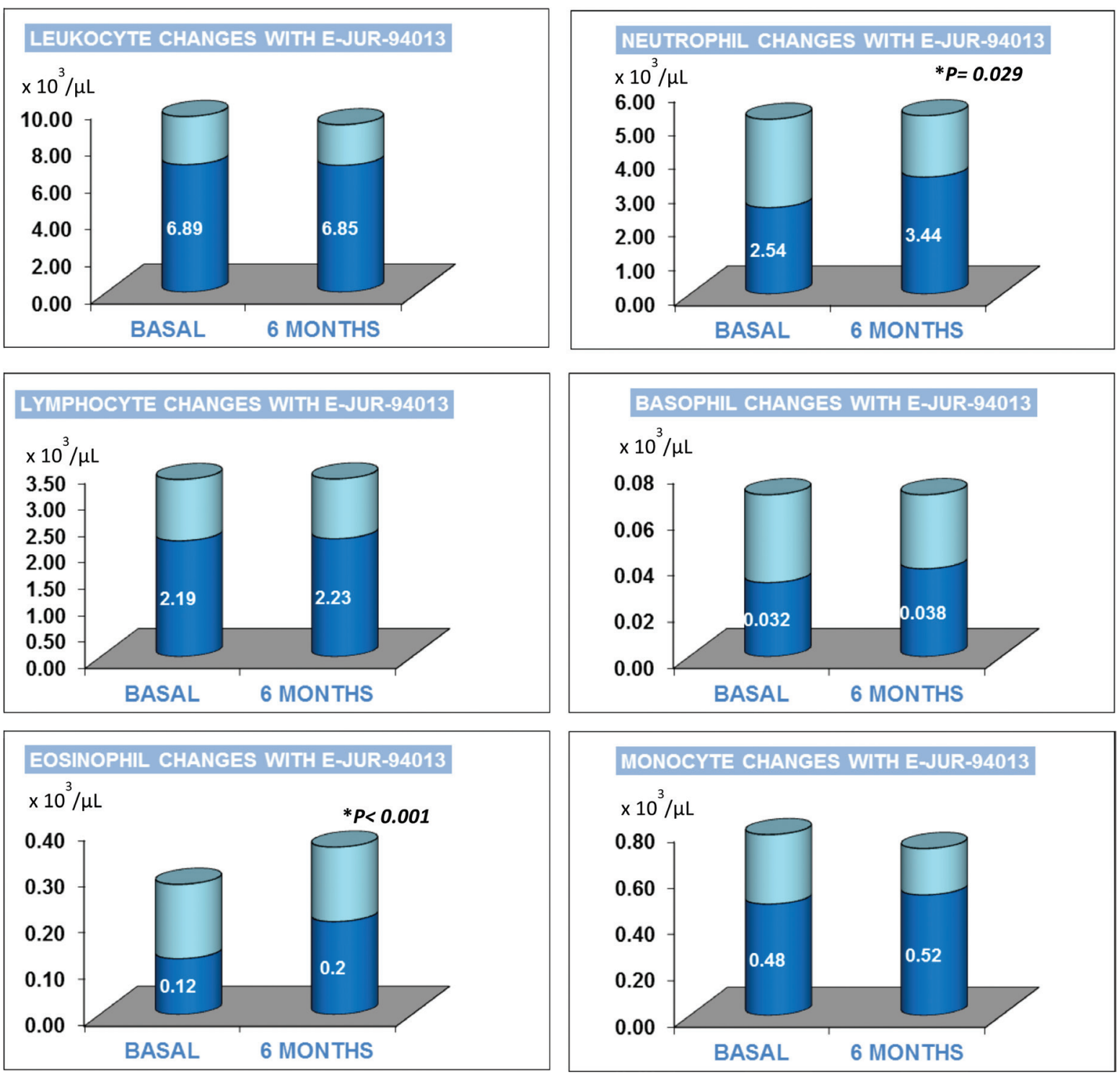

Fig. 2. Leukocyte changes with $750 \mathrm{mg} /$ day (3 capsules) of DefenVid ${ }^{\circledR}$ for 6 months. Data are expressed as mean \pm SD.

Electrophoresis techniques were used to observe the lipoprotein nature of the extract and to confirm the nondenaturing properties of the techniques applied. A rigorous manufacturing process, controlled at different points, guarantees the quality of the extract and of the final packaged product on the market, Defen$\operatorname{Vid}{ }^{\circledR}$. Complex analysis of different fractions was performed to detect the active ingredient responsible for this effect, and we concluded that the isolated fraction corresponding to amino acid 4,5,6,7-tetrahydroimidazo[4,5-c]pyridine-6-carboxylic acid (spinacin) could be responsible for the immunomodulatory activity observed in in vitro tests.

The evaluation of acute and chronic toxicity did not reflect any toxic effects derived from the extract. The first study in laboratory rats to determine the effect of the extract in the diet, showed a short-term stimulatory effect of the immune system, manifesting an increase in total and subclasses of leukocytes in the group treated with E-JUR-94013 for a month. ${ }^{44}$ In a second study, 300 farm piglets were divided into 15 groups and treated with five dif- ferent diets with fish extracts, including E-JUR-94013, as a supplement to a commercial diet, for 42 days. Data analysis confirmed an increase in immune cells (cellular immunity), in addition to an active response in the serum immunoglobulin levels (humoral immunity). ${ }^{43}$

To demonstrate the immunostimulatory effect of E-JUR-94013 observed in animals, an in vitro assay was conducted in E-JUR94013-treated human lymphocyte cultures for 2 days. ${ }^{42}$ The results obtained by measuring different markers of lymphocyte activation by flow cytometry revealed significant immunoactivation compared with the control group and with other known lymphocyte inducers, proving it a potent immunoregulatory agent. A significant reduction in the percentage of apoptotic cells was also observed in lymphocyte cultures treated with E-JUR-94013, reflecting an extract-associated increased cell viability. The beneficial effect of different oily fish-extracted molecules on the immune system has been published on numerous occasions. The main objective of the present study, coalescing previous animal 

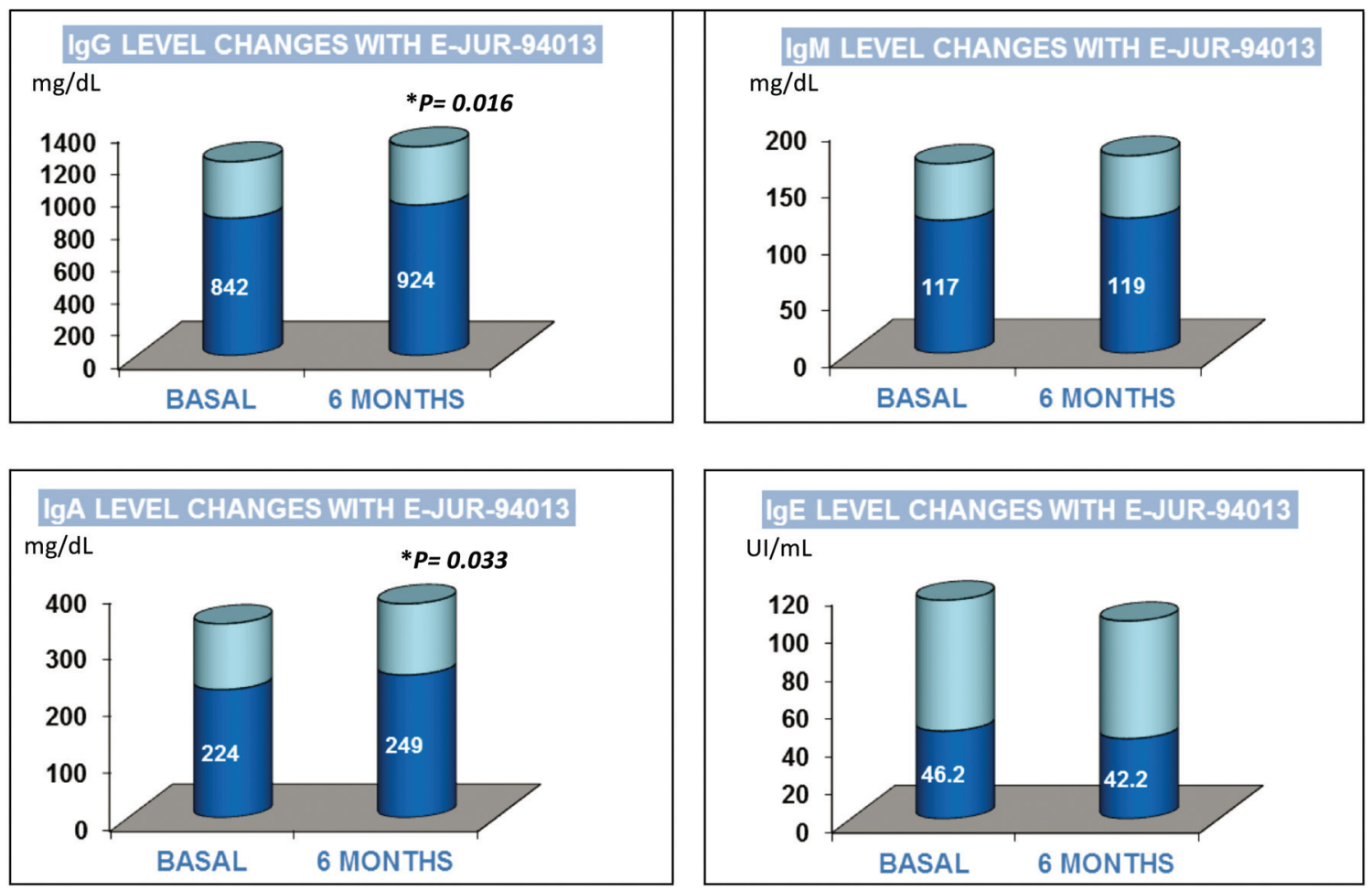

Fig. 3. Serum immunoglobulin levels after $750 \mathrm{mg} /$ day ( 3 capsules) of DefenVid ${ }^{\circledR}$ for 6 months. Data are expressed as mean \pm SD.

study data, was to determine whether the immunostimulant effect of DefenVid® (E-JUR-94013) could be confirmed in humans.

\section{Methods and results}

\section{Study \#1}

\section{Subjects}

Fifty-six subjects were supplemented with $750 \mathrm{mg} /$ day (3 capsules) of DefenVid $\AA$ for 6 months. During the study period, none of these patients were taking any drug or nutraceutical affecting the immune system.

\section{Results}

An increase in the cell number of all leukocyte subclasses was observed, with a significant increase in the number of neutrophils $(p<0.03)$ and eosinophils $(p<0.001)$ (Fig. 2). Serum immunoglobulin A $(p=0.033), \mathrm{G}(p=0.016)$ and M levels were also increased, while displaying a slight reduction in the concentration of IgE, a protein related to allergies (Fig. 3). Previous studies had linked the blue fish supplement to a preventative effect on childhood allergies. ${ }^{45}$ To demonstrate the effect of DefenVid ${ }^{\circledR}$ in patients with immunodeficiency, patients with $<5,000$ leukocytes/ $\mu \mathrm{L}$ were selected. After 6 months of treatment with DefenVid $\AA$, a significant increase in the total leukocyte count was observed ( $p=$ 0.023 ), with a moderate increase in all of the white cell subclasses
(Fig. 4).

\section{Study \#2}

Subjects

A larger study was performed in 205 patients with immune system problems, while maintaining the hypothesis that DefenVid $\mathbb{}$ might be useful to enhance their defense mechanisms. Patients aged $68.41 \pm 9.11$ years were grouped according to the number of leukocytes (total or subclasses), high or low relative to our refer-

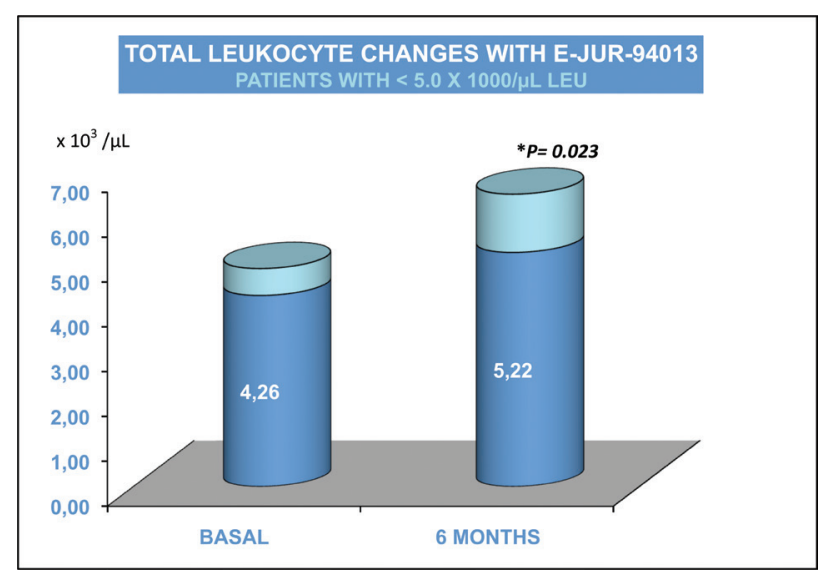

Fig. 4. Leukocyte increase in patients with immunodeficiency after 6-month treatment with DefenVid $^{\circledR}$. Data are expressed as mean \pm SD. 

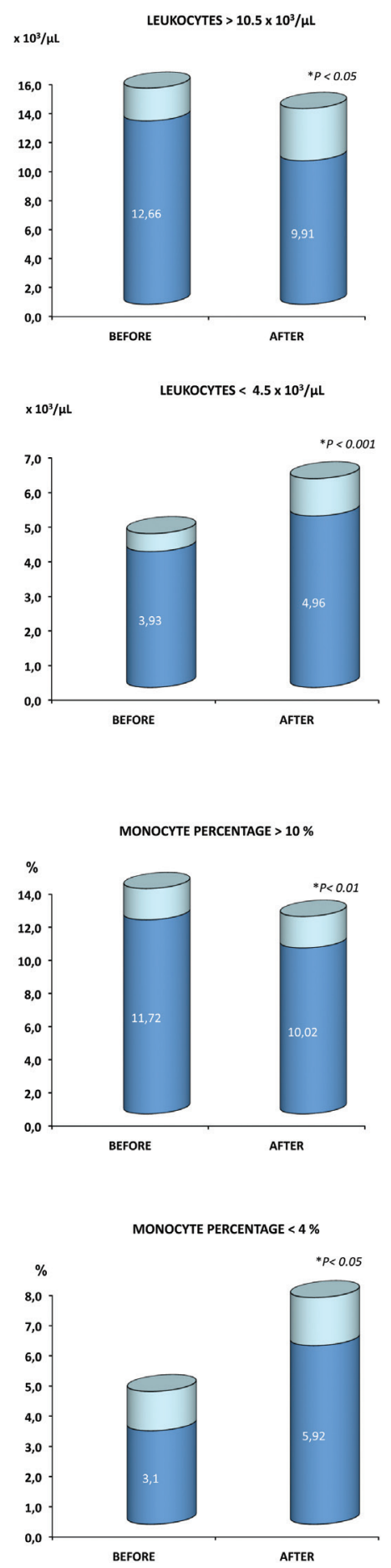
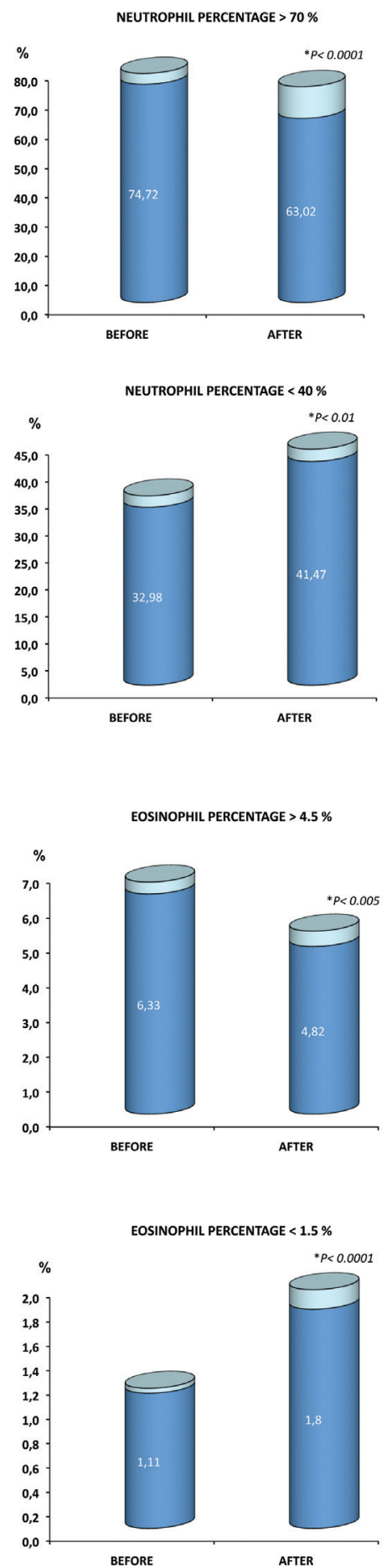
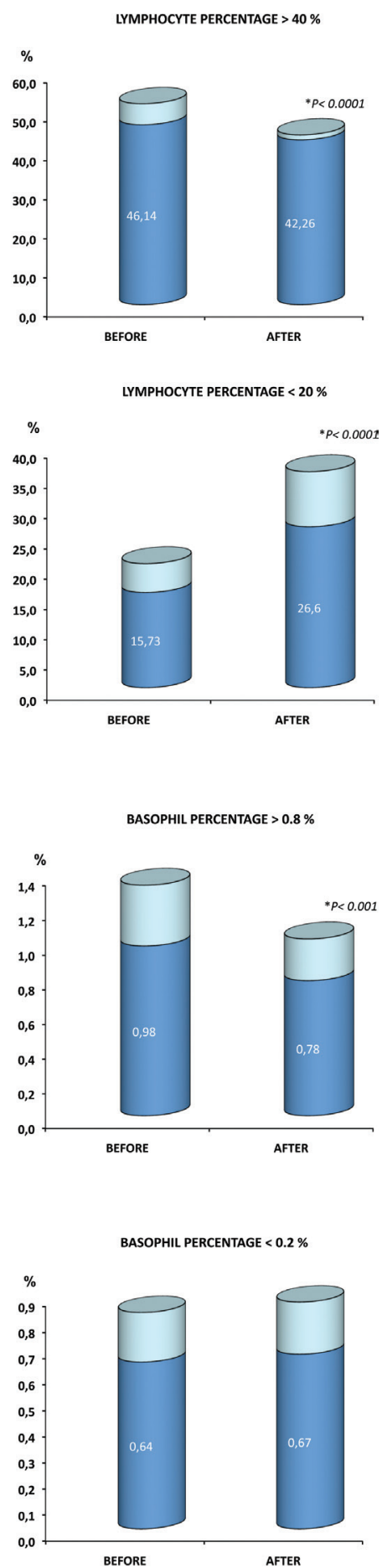

Fig. 5. Leukocyte changes in patients with immune system dysfunction after 3-month treatment with DefenVid ${ }^{\circledR}$. Data are expressed as mean \pm SE.

ence ranges. Patients were treated daily with a $750 \mathrm{mg}(3$ capsules/ day) dose of DefenVid® for a 3-month period.

Results

The data showed an interesting immunomodulatory effect, not previously found, demonstrating an increase in white cells in the immunodeficient patients and a decrease in the percentage of white cells in the group with high leukocyte counts at baseline, bringing the white cell count to within normal ranges in both cases $(p<$ 0.05) (Fig. 5). Serum immunoglobulin levels were also affected positively, as observed in the increase in IgA, IgG and IgM and a decrease in the levels of IgE (Fig. 6). 


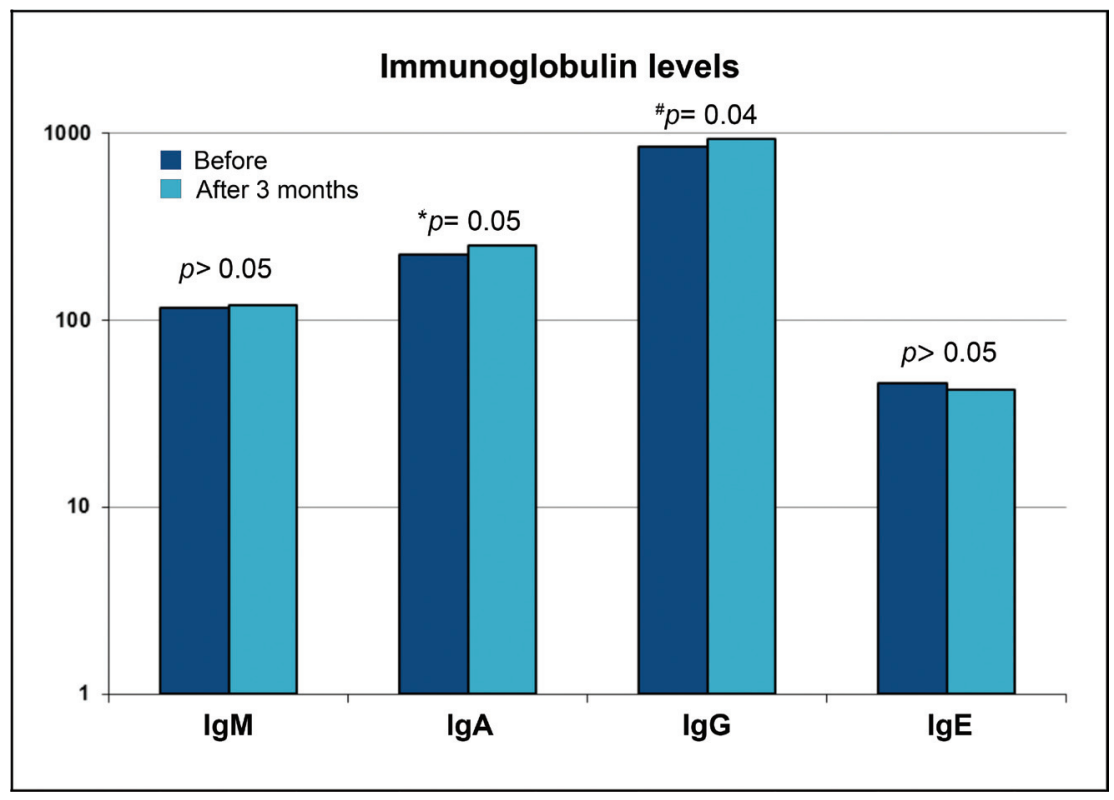

Fig. 6. Serum IgA, IgG and IgM, and total IgE after 3-month treatment with DefenVid ${ }^{\oplus}$. Data are expressed as mean (IgA, IgG and IgM in mg/dL; IgE in UI/ $\mathrm{mL})$.

\section{Study \#3}

\section{Subjects}

One thousand five-hundred randomly selected subjects aged 1-98 years were treated for 3 months with a multifactorial therapy, with a single common factor: DefenVid ${ }^{\circledR}$. A descriptive analysis of the data was performed, presenting the baseline and posttreatment values, case by case.

\section{Results}

The infographics demonstrated the regulatory effect of DefenVid $\AA$ on the total leukocyte count and the percentage of neutrophils, lymphocytes, monocytes and eosinophils, showing a modulating effect in the extreme cases (Fig. 7). Low counts (on the left) increased, and high counts (on the right side of the graph) decreased, reaching normal immunity values. To understand whether this

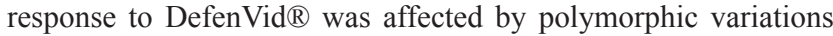
of genes involved in immune regulation of inflammation, the genotypes IL1B-T3954C, IL6C573G, IL6R-A1510C and TNFA$G 308 A$ were determined, and a genotype-dependent response was observed (Fig. 8). The ultrasensitive C-reactive protein (us-CRP) levels, used as an indirect biochemical marker of inflammation status, were also measured. The results indicated that high us-CRP values decreased, reaching normal values in many cases (Fig. 9).

\section{Discussion and conclusions}

In previous data we had observed a DefenVid®-related immunoactivating effect in animals and human peripheral lymphocyte cultures, ${ }^{42-44}$ and now we can confirm the same response in an extensive human sample. Our hypothesis, considering DefenVid $\AA$ to be a useful complement to enhance the immune system in im- munodepressed patients, has been consolidated in several populations of different ages.

Numerous scientific studies have demonstrated the beneficial use of nutritional supplements in immune system function in healthy subjects and in immunodepressed patients. Schmoranzer et al. ${ }^{45}$ published that supplementation with a complex micronutrient formulation increases the number of various types of immune cells and decreases total and low-density lipoprotein cholesterol in elderly people. Immunonutrition based on arginine, omega-3 fatty acids, and RNA reduced stress-induced immunosuppression and multiple micronutrient supplements have been reported to reduce morbidity and mortality in human immunodeficiency virus-infected pregnant women and their offspring, ${ }^{46}$ and also improved early child growth in a large randomized controlled trial in Africa. ${ }^{47}$

The biological mechanisms of action are not clear and depend on the nature of the nutrients. Fish oil-enriched food has been significantly related to an increase in the percentage of eicosapentaenoic in phospholipids of white blood cells and the immune response to lipopolysaccharide within 1 week in healthy subjects. ${ }^{48}$ Recently, much research has focused on regulatory $\mathrm{T}$ cells as controllers of immune responses not only to self-antigens but also to non-self-antigens, ${ }^{49}$ the modulation of Th1/Th2 differentiation and Th17 response being an important key in this immunologic effect, according to Suzuki et al. ${ }^{46}$ Other authors reported that absorption of long-chain fatty acids stimulates lymphocyte flux and lymphocyte blastogenesis in intestinal lymphat$\mathrm{ics}^{50}$ and that lipoproteins are involved in the stimulation of lymphocyte function by both receptor-dependent and -independent mechanisms.

Regardless of the mechanism of action, all these studies show that nutritional lipoprotein supplement intake may modulate intestinal immune function. Since the first level of defense takes place at the intestinal lumen-mucosa for oral supplementations and innate immunity in the small intestine is mainly characterized by IgA secretion, ${ }^{51}$ our group suggest that DefenVid $\AA$ might act on the systemic immune system by modulating lymphocyte action and 
DefenVid-induced Leukocyte Number Variation

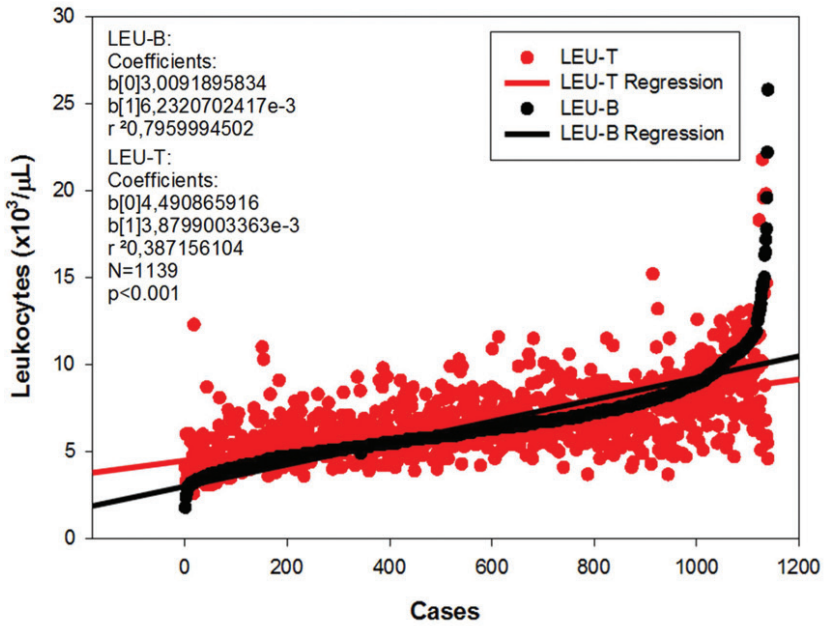

DefenVid-induced Lymphocyte (\%) Variation

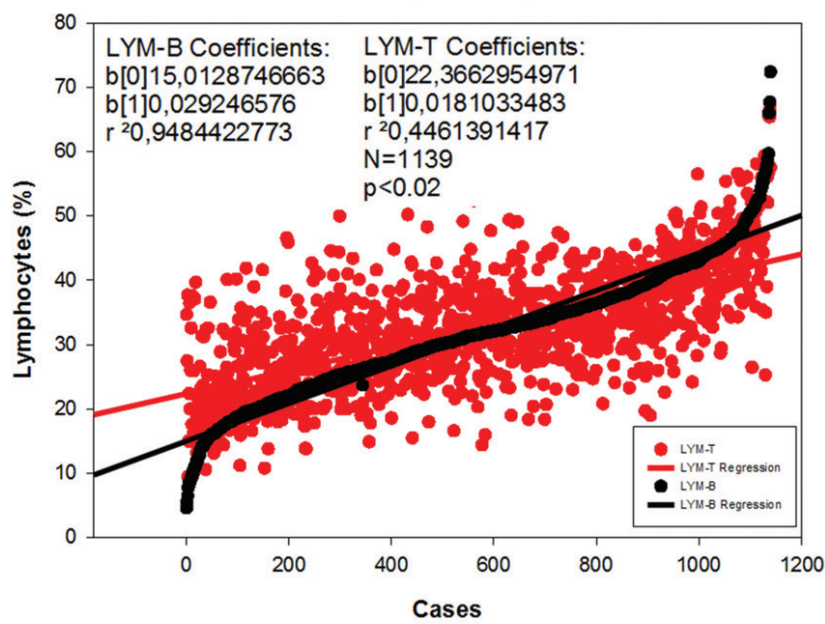

DefenVid-induced Eosinophil (\%) Variation

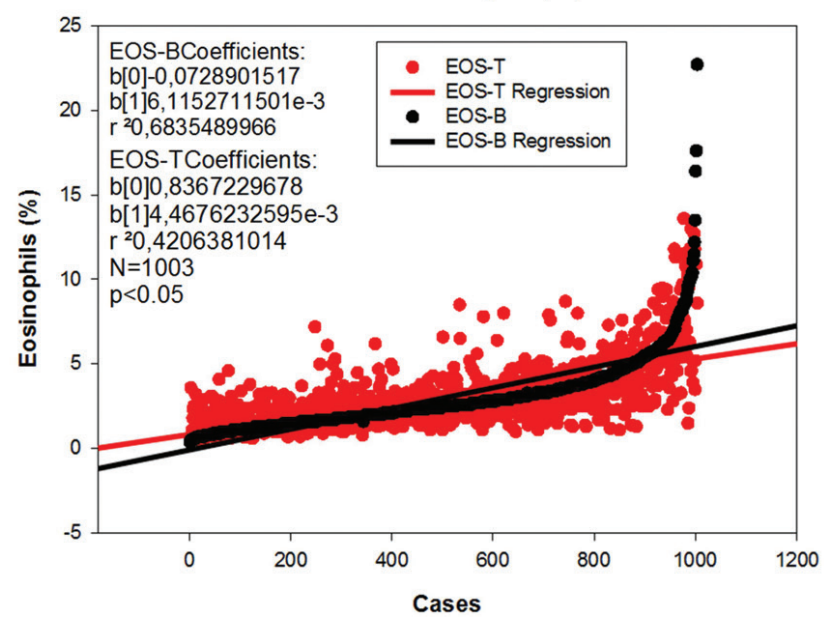

DefenVid-induced Neutrophil (\%) Variation

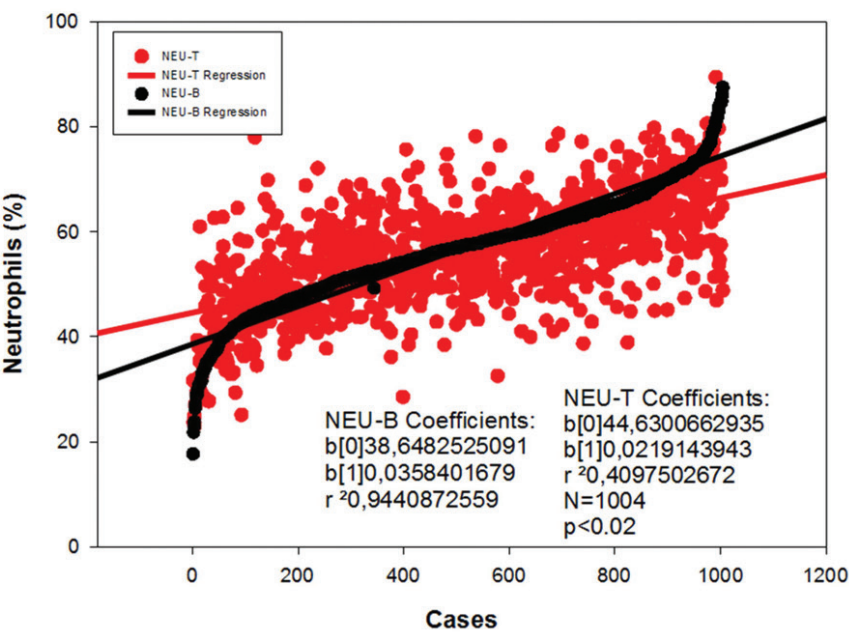

DefenVid-induced Monocyte (\%) Variation

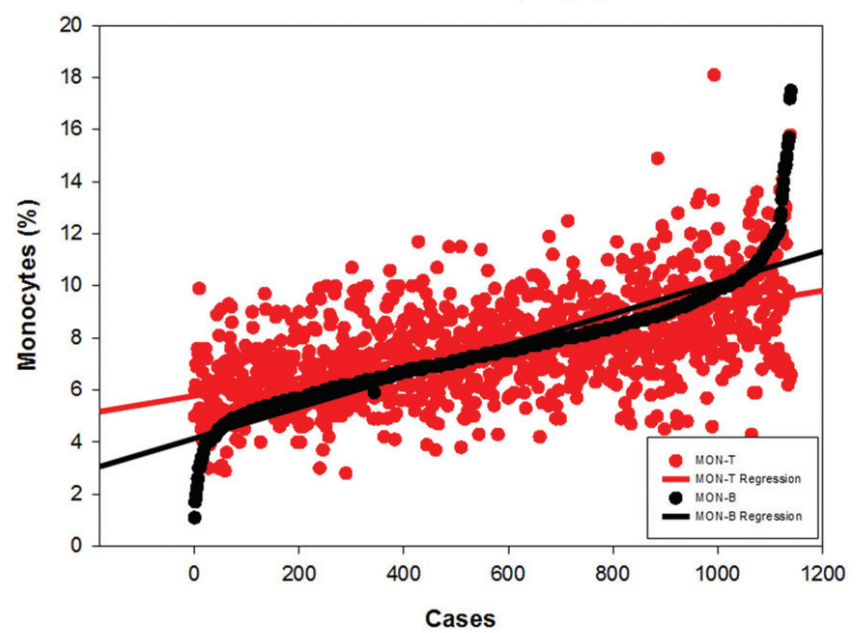

Fig. 7. Case-by-case graphics showing the regulatory effect of DefenVid ${ }^{\circledR}$ on total leukocyte counts and percentage of neutrophils, lymphocytes, monocytes and eosinophils. A significant modulating effect can be observed in the extreme cases. 


\section{IL1B-T3954C Genotype-Related Leukocyte Number Variation induced by DefenVid}

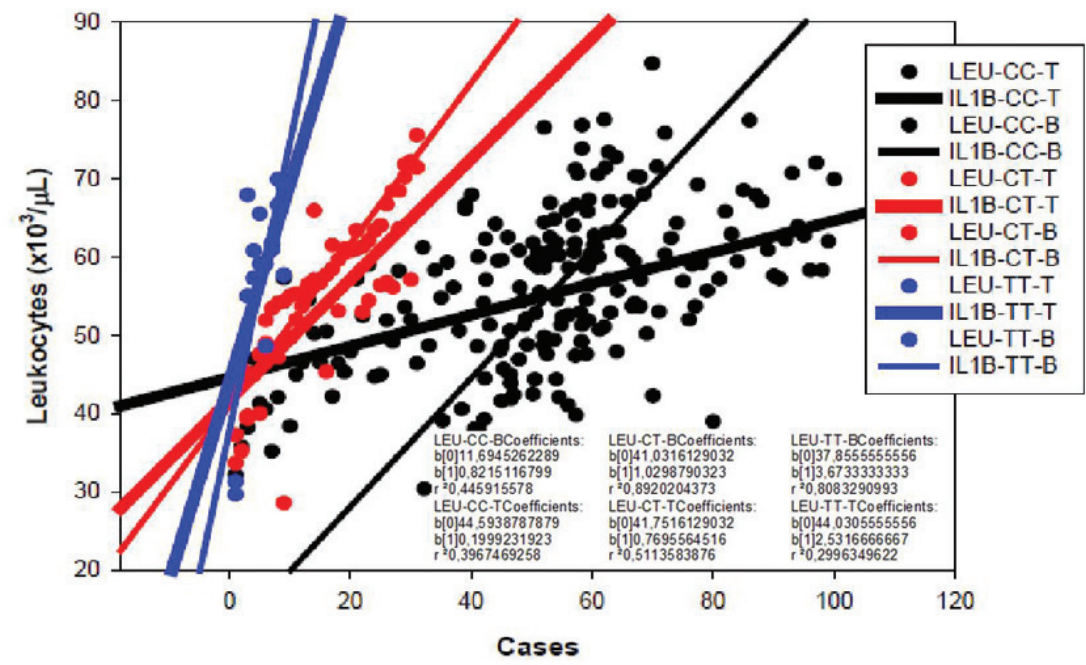

\section{IL6-C573G-Related Leukocyte Number Variation induced by DefenVid}

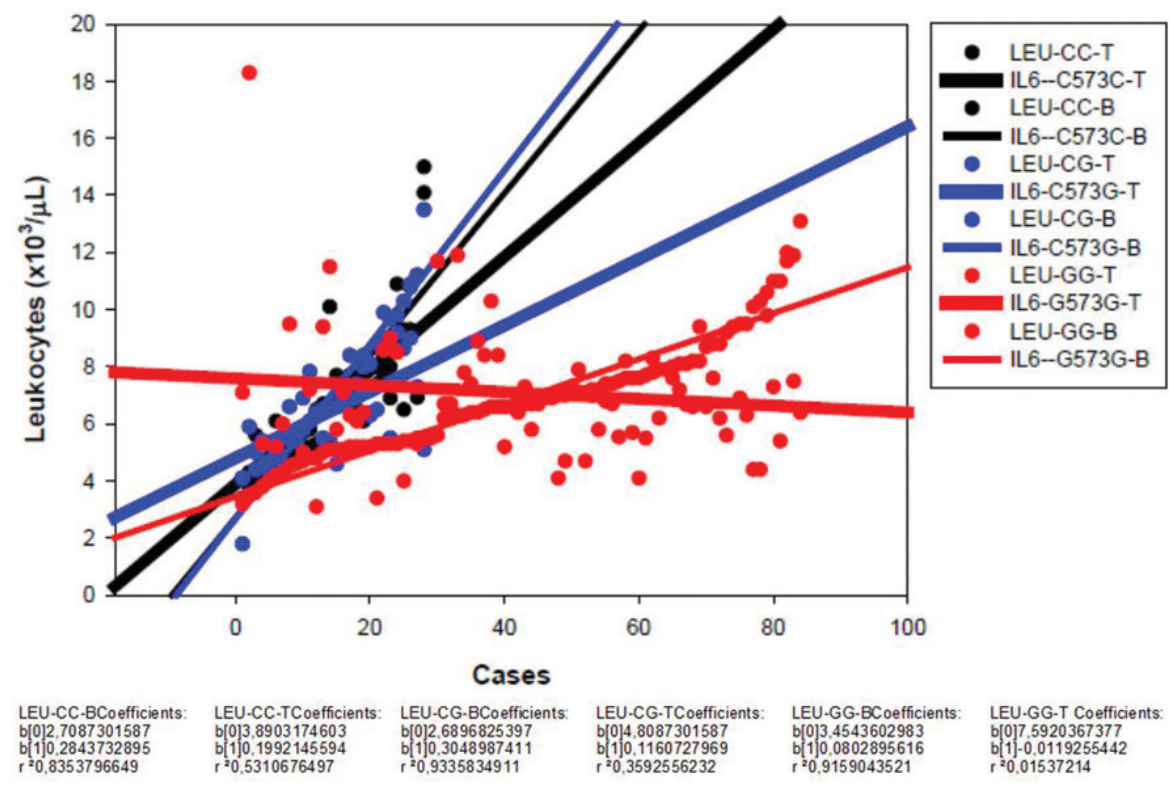

Fig. 8. IL1B-T3954C and IL6-C573G genotype-dependent responses of DefenVid ${ }^{\circledR}$.

intestinal immune function at IgA level. ${ }^{43}$

Data analysis from human studies showed a DefenVid®-related immunomodulatory effect that we had not assessed in animals or in vitro studies. In patients presenting high leukocyte counts, we observed a significant decrease in the total and leukocyte subclasses and a positive modulation in serum Ig levels after 3-month treatment with DefenVid ${ }^{\circledR}$. It has been hypothesized that the activation of cytokines and resulting inflammation may play a role in the development of autoantibodies and subsequent progression to autoimmune diseases. In our studies, increase of inflammation markers such as CRP and/or proinflammatory cytokines and chemokines was not observed, suggesting that the increase in total IgG, IgA and IgM antibodies and not in autoantibody levels had a positive effect on the immune system.

In addition, intravenous immunoglobulin, originally developed for replacement therapy in humoral immunodeficiency syndromes, has more recently become an important therapeutic modality in severe autoimmune disorders, such as neuroimmunological diseases like Guillain-Barré syndrome, ${ }^{50}$ systemic lupus erythematosus, ${ }^{51}$ certain forms of vasculitis, ${ }^{52}$ and polymyositis/dermatomyositis. ${ }^{53}$ The mechanism of action remains unclear, but intravenous immunoglobulin may block the function of Fc receptors expressed by phagocytes of the reticuloendothelial system, and also induces the inhibitory Fc receptor (Fc $\gamma$ RIIB) expression on infiltrating mac- 


\section{DefenVid-induced C-Reactive Protein variation}

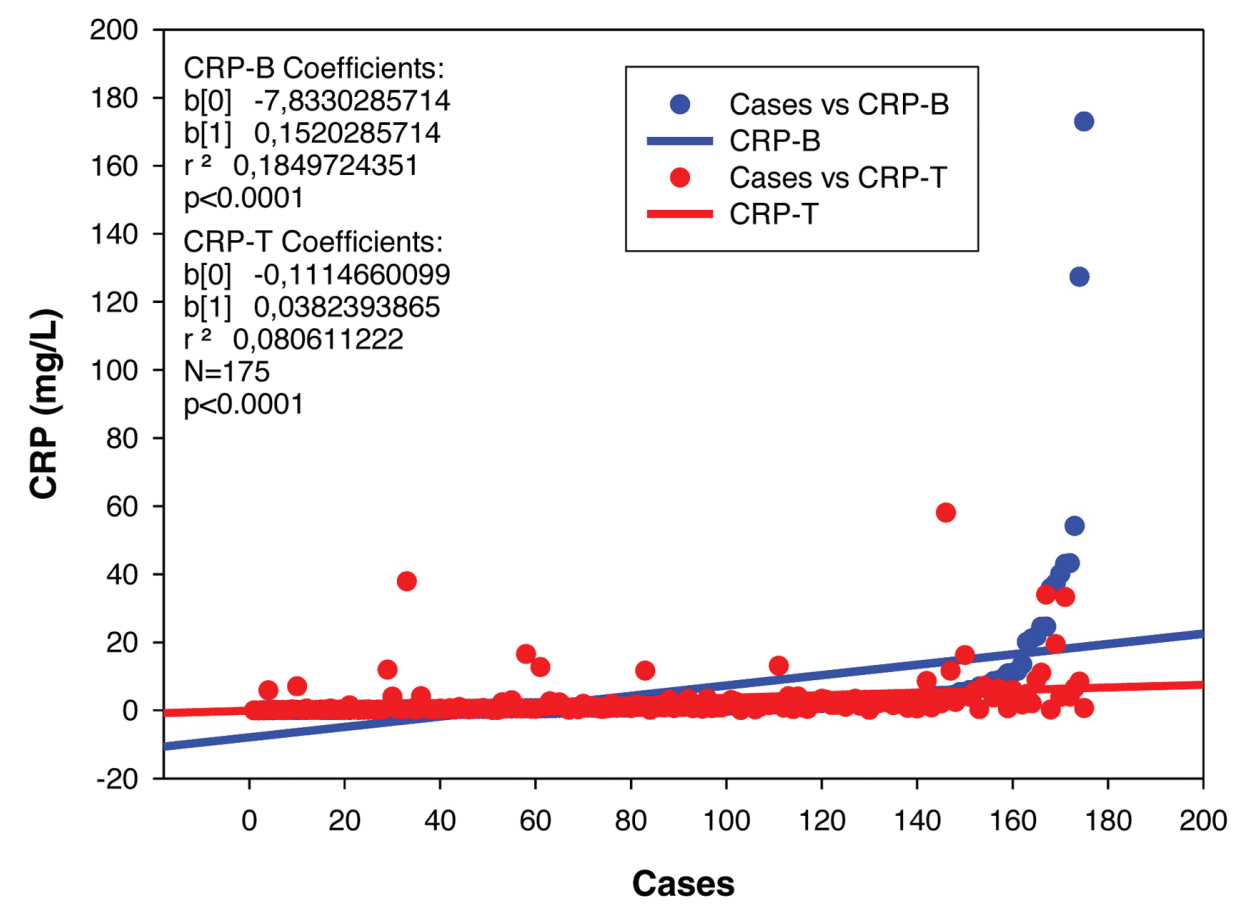

Fig. 9. DefenVid ${ }^{\circledR}$-associated regulation of C-reactive protein.

rophages in the $\mathrm{K} / \mathrm{BxN}$ model of rheumatoid arthritis. An additional mode of action may involve the presence of antiidiotypic antibodies that block the antigen combining sites of pathogenic antibodies.

A fish oil-supplemented diet has been demonstrated to be beneficial in the following pathologies: preventing or ameliorating inflammatory bowel disease ${ }^{54-56}$; protecting against impaired lung function and chronic obstructive pulmonary disease, especially in male smokers ${ }^{57}$; attenuating inflammatory processes, oxidative stress and metabolism ${ }^{58}$; slowing development of rheumatoid arthritis and reducing disease severity ${ }^{59}$; and, decreasing the allergic response, ${ }^{60}$ among other pathologies. As occurs with drugs and other nutritional supplements, ${ }^{61,62}$ the personal genotype profile exerts an important effect on the interindividual response to DefenVid ${ }^{\circledR}$.

According to our results, we conclude that DefenVid $\AA$ may be considered to be a nutritional supplement with a rapid response in the recovery of immune status, making it a highly beneficial dietary supplement for those persons presenting low defense mechanisms or immune problems, both in humoral and cellular immunity. In addition, DefenVid $\AA$ might help in the management of some pathologies such as inflammatory, allergic or autoimmune disorders. Further work comparing the responses to DefenVid $\AA$ versus a control compound would be very interesting to support these results.

\section{Future prospects}

In regions such as western Europe, the use of low-value species for food markets offers major opportunities for new biotechnology options. A particular challenge for marine-derived compounds is the degree to which synergistic effects can be not only conclusively demonstrated but also realistically defined for biotechnological intervention. Otherwise, increasing understanding of what the active components in marine organisms are and how they work will simply lead to their isolation as marine-derived drugs, and biotechnological interest in the marine organisms and whole extracts from them will not be justifiable.

Among the different factors that can support chronic inflammation, nutrition plays a pivotal and fascinating role. Indeed, nutrition, acting on immune system and inflammation, can be a trigger for both pathogenic and protective processes during the entire lifespan. Accordingly, nutrition is probably the most powerful tool that we have to modulate the immune system response, towards an enhancement of health status of the general population. In this framework, one of the most fascinating immune-regulation strategies seems to be the possibility to decrease inflammation without compromising its physiological role, fundamental for survival.

To this aim, it is urgent to clarify the shady areas of the complex mechanisms involved in the chronic inflammation status in order to carry out targeted therapeutic interventions. At present, one possible intervention could be represented by a whole diet approach and/or by a nutraceutical approach that, acting on digestive processes and immune systems, is able to modulate the inflammatory and degenerative processes of the body. Indeed, ad hoc dietary adjustments, such as reducing or eliminating saturated and trans fat, or increasing the intake of omega-3 fat, vitamins, micronutrients and antioxidants, can help minimize inflammation. Similarly, lipofishins, when adequately administered, as well as potential manipulation of the gut microbiota such as intestinal microbiota transfer, could confer beneficial effects to the host by influencing the gut microbiota composition and directly affecting the inflammatory state and metabolic disturbances related to inappropriate 
nutrition and diet in humans.

\section{Conflict of interest}

The authors have no conflict of interests related to this publication.

\section{Author contributions}

Study design (VL, LC, IC, RC), performance of experiments (VL, IC), analysis and interpretation of data (IC, VL, LC, RC), manuscript writing (VL, IC), critical revision (LC, RC), statistical analysis (VL, LC), critical funding (RC), administration (VL, IC), technical or material support (VL, IC).

\section{References}

[1] Costello MJ, Chaudhary C. Marine biodiversity, biogeography, deep-sea gradients, and conservation. Curr Biol 2017;27(13):2051. doi:10.1016/j.cub.2017.06.015.

[2] Bowen BW, Rocha LA, Toonen RJ, Karl SA, ToBo Laboratory. The origins of tropical marine biodiversity. Trends Ecol Evol 2013;28(6):359366. doi:10.1016/j.tree.2013.01.018.

[3] Baker DD, Alvi KA. Small-molecule natural products: new structures, new activities. Curr Opin Biotechnol 2004;15(6):576-583. doi:10.1016/j.copbio.2004.09.003.

[4] Kobayashi J. Search for new bioactive marine natural products and application to drug development. Chem Pharm Bull (Tokyo) 2016;64(8):1079-1083. doi:10.1248/cpb.c16-00281.

[5] Fernando IP, Kim M, Son KT, Jeong Y, Jeon YJ. Antioxidant activity of marine algal polyphenolic compounds: a mechanistic approach. J Med Food 2016;19(7):615-628. doi:10.1089/jmf.2016.3706.

[6] Lindequist U. Marine-derived pharmaceuticals - challenges and opportunities. Biomol Ther (Seoul) 2016;24(6):561-571. doi:10.4062/ biomolther.2016.181.

[7] Anjum K, Abbas SQ, Shah SA, Akhter N, Batool S, Hassan SS. Marine sponges as a drug treasure. Biomol Ther (Seoul) 2016;24(4):347362. doi:10.4062/biomolther.2016.067.

[8] Cooper EL, Yao D. Diving for drugs: tunicate anticancer compounds. Drug Discov Today 2012;17(11-12):636-648. doi:10.1016/j. drudis.2012.02.006

[9] Januar HI, Zamani NP, Soedharma D, Chasanah E. New cytotoxic cembranoid from indonesian soft coral sarcophyton sp. Pharmacognosy Res 2017;9(1):65-68. doi:10.4103/0974-8490.199779.

[10] Hassan SSU, Shaikh AL. Marine actinobacteria as a drug treasure house. Biomed Pharmacother 2017;87:46-57. doi:10.1016/j.biopha.2016.12.086.

[11] El-Hossary EM, Cheng C, Hamed MM, El-Sayed Hamed AN, Ohlsen $\mathrm{K}$, Hentschel $\mathrm{U}$, et al. Antifungal potential of marine natural products. Eur J Med Chem 2017;126:631-651. doi:10.1016/j.ejmech.2016.11.022.

[12] Hassan SS, Anjum K, Abbas SQ, Akhter N, Shagufta BI, Shah SA Tasneem U. Emerging biopharmaceuticals from marine actinobacteria. Environ Toxicol Pharmacol 2017;49:34-47. doi:10.1016/j. etap.2016.11.015.

[13] Tiwari A, Gupta VG, Bakhshi S. Newer medical therapies for metastatic soft tissue sarcoma. Expert Rev Anticancer Ther 2017;17(3):257270. doi:10.1080/14737140.2017.1285229.

[14] Cheng T, Zhu Z, Masuda S, Morcos NC. Effects of multinutrient supplementation on antioxidant defense systems in healthy human beings. J Nutr Biochem 2001;12(7):388-395. doi:10.1016/S09552863(01)00153-X.

[15] Viladomiu M, Hontecillas R, Yuan L, Lu P, Bassaganya-Riera J. Nutritional protective mechanisms against gut inflammation. J Nutr Biochem 2013;24(6):929-939. doi:10.1016/j.jnutbio.2013.01.006.

[16] Kotecha R, Takami A, Espinoza JL. Dietary phytochemicals and can- cer chemoprevention: a review of the clinical evidence. Oncotarget 2016;7(32):52517-52529. doi:10.18632/oncotarget.9593.

[17] Dunn J, Rao S. Epigenetics and immunotherapy: The current state of play. Mol Immunol 2017;87:227-239. doi:10.1016/j.molimm.2017.04.012.

[18] Weinmann H. Cancer immunotherapy: Selected targets and smallmolecule modulators. Chem Med Chem 2016;11(5):450-466. doi:10.1002/cmdc.201500566.

[19] Serviddio G, Bellanti F, Villani R, Tamborra R, Zerbinati C, Blonda M, et $a l$. Effects of dietary fatty acids and cholesterol excess on liver injury: A lipidomic approach. Redox Biol 2016;9:296-305. doi:10.1016/j.redox.2016.09.002.

[20] Kurt A, Andican G, Siva ZO, Andican A, Burcak G. The effects of $n-3$ long-chain polyunsaturated fatty acid supplementation on AGEs and sRAGE in type 2 diabetes mellitus. J Physiol Biochem 2016;72(4):679687. doi:10.1007/s13105-016-0506-4.

[21] Cho JH, Kim IH. Fish meal - nutritive value. J Anim Physiol Anim Nutr 2010;95(6):685-692. doi:10.1111/j.1439-0396.2010.01109.x.

[22] Cave MC, Hurt RT, Frazier TH, Matheson PJ, Garrison RN, McClain $\mathrm{CJ}$, et al. Obesity, inflammation, and the potential application of pharmaconutrition. Nutr Clin Pract 2008;23(1):16-34. doi:10.1177/011542650802300116.

[23] Sandhu N, Schetter SE, Liao J, Hartman TJ, Richie JP, McGinley J, et al. Influence of obesity on breast density reduction by omega-3 fatty acids: Evidence from a randomized clinical trial. Cancer Prev Res (Phila) 2016;9(4):275-282. doi:10.1158/1940-6207.CAPR-15-0235.

[24] McEwen BJ, Morel-Kopp MC, Chen W, Tofler GH, Ward CM. Effects of omega-3 polyunsaturated fatty acids on platelet function in healthy subjects and subjects with cardiovascular disease. Semin Thromb Hemost 2013;39(1):25-32. doi:10.1055/s-0032-1333309.

[25] Whelton SP, Silverman MG, McEvoy JW, Budoff MJ, Blankstein R, Eng $\mathrm{J}$, et al. Predictors of long-term healthy arterial aging: Coronary artery calcium nondevelopment in the MESA study. JACC Cardiovasc Imaging 2015;8(12):1393-1400. doi:10.1016/j.jcmg.2015.06.019.

[26] Ruggiero C, Lattanzio F, Lauretani F, Gasperini B, Andres-Lacueva C, Cherubini A. Omega-3 polyunsaturated fatty acids and immune-mediated diseases: Inflammatory bowel disease and rheumatoid arthritis. Curr Pharm Des 2009;15(36):4135-4148. doi:10.2174/138161209789909746.

[27] Noga EJ, Silphaduang U, Park NG, Seo JK, Stephenson J, Kozlowicz S. Piscidin 4, a novel member of the piscidin family of antimicrobial peptides. Biochem Mol Biol 2009;152(4):299-305. doi:10.1016/j. cbpb.2008.12.018.

[28] Tomasinsig L, Benincasa M, Scocchi M, Skerlavaj B, Tossi A, Zanetti M, et al. Role of cathelicidin peptides in bovine host defense and healing. Probiotics Antimicrob Proteins 2010;2(1):12-20. doi:10.1007/ s12602-010-9035-6.

[29] Wang X, Meng J, Zhou T, Zhang Y, Yang B, Xi M, et al. Antimicrobial susceptibility testing and genotypic characterization of Staphylococcus aureus from food and food animals. Foodborne Pathog Dis 2012;9(2):95-101. doi:10.1089/fpd.2011.0987.

[30] Wang WY, Lee SY, Chiueh TS, Lu JJ. Molecular and phenotypic characteristics of methicillin-resistant and vancomycin-intermediate staphylococcus aureus isolates from patients with septic arthritis. J Clin Microbiol 2009;47(11):3617-3623. doi:10.1128/JCM.00539-09.

[31] López-Expósito I, Recio I. Protective effect of milk peptides: antibacterial and antitumor properties. Adv Exp Med Biol 2008;606:271293. doi:10.1007/978-0-387-74087-4_11.

[32] Phelan M, Aherne SA, Wong A, O'Brien NM. Bioactive properties of wood knot extracts on cultured human cells. J Med Food 2009;12(6):1245-1251. doi:10.1089/jmf.2008.0125.

[33] Wiesner J, Vilcinskas A. Antimicrobial peptides: The ancient arm of the human immune system. Virulence 2010;1(5):440-464. doi:10.4161/viru.1.5.12983.

[34] Marahiel MA. Working outside the protein-synthesis rules: insights into nonribosomal peptide synthesis. J Pept Sci 2009;15(12):799807. doi:10.1002/psc.1183.

[35] Boman HG. Antibacterial peptides: basic facts and emerging concepts. J Intern Med 2003;254(3):197-215. doi:10.1046/j.13652796.2003.01228.x.

[36] Cormican P, Meade KG, Cahalane S, Narciandi F, Chapwanya A, Lloyd AT, et al. Evolution, expression and effectiveness in a cluster of novel 
bovine beta-defensins. Immunogenetics 2008;60(3-4):147-156. doi:10.1007/s00251-007-0269-8.

[37] Conlon JM, Sonnevend A. Antimicrobial peptides in frog skin secretions. Methods Mol Biol 2010;618:3-14. doi:10.1007/978-1-60761594-1_1.

[38] Hancock RE, Sahl HG. Antimicrobial and host-defense peptides as new antiinfective therapeutic strategies. Nat Biotechnol 2006;24(12):1551-1557. doi:10.1038/nbt1267.

[39] Steinstraesser L, Hauk J, Al-Benna S, Langer S, Ring A, Kesting M, et al. Genotoxic and cytotoxic activity of host defense peptides against human soft tissue sarcoma in an in vitro model. Drug Chem Toxicol 2012;35(1):96-103. doi:10.3109/01480545.2011.589441.

[40] Garofalo R. Cytokines in human milk. J Pediatr 2010;156(2 Suppl):S36-S40. doi:10.1016/j.jpeds.2009.11.019.

[41] Zhang L, Falla TJ. Potential therapeutic application of host defense peptides. Methods Mol Biol 2010;618:303-327. doi:10.1007/978-160761-594-1_19.

[42] Lombardi VRM, Fernández-Novoa L, Etcheverría I, Seoane S, Cacabelos R. Effects of fish-derived lipoprotein extracts on activation markers Fas expression and apoptosis in peripheral blood lymphocytes. Int Immunopharmacol 2005;5:253-262. doi:10.1016/j.intimp.2004.09.034.

[43] Lombardi VR, Fernández-Novoa L, Corzo D, Zas R, Cacabelos R. Enhancement in immune function and growth using E-JUR-94013 supplementation. Methods Find Exp Clin Pharmacol 2002;24(9):573578. doi:.

[44] Lombardi V, Cagiao A, Fernández-Novoa L, Alvarez XA, Corzo D, Zas $\mathrm{R}$, et al. Short term food supplementation effects of a fish derived extract on the immunological status of pregnant rats and their sucking pups. Nutr Res 2001;21(11):1425-1434. doi:10.1016/S02715317(01)00361-X.

[45] Schmoranzer F, Fuchs N, Markolin G, Carlin E, Sakr L, Sommeregger $U$. Influence of a complex micronutrient supplement on the immune status of elderly individuals. Int J Vitam Nutr Res 2009;79(5-6):308318. doi:10.1024/0300-9831.79.56.308.

[46] Suzuki D, Furukawa K, Kimura F, Shimizu H, Yoshidome H, Ohtsuka M, et al. Effects of perioperative immunonutrition on cellmediated immunity, T helper type 1 (Th1)/Th2 differentiation, and Th17 response after pancreaticoduodenectomy. Surgery 2010;148(3):573-581. doi:10.1016/j.surg.2010.01.017.

[47] Irlam JH, Visser MM, Rollins NN, Siegfried N. Micronutrient supplementation in children and adults with HIV infection. Cochrane Database Syst Rev 2010;(12):CD003650. doi:10.1002/14651858. CD003650.pub3.

[48] Faber J, Berkhout M, Vos AP, Sijben JW, Calder PC, Garssen J, et al. Supplementation with a fish oil-enriched, high-protein medical food leads to rapid incorporation of EPA into white blood cells and modulates immune responses within one week in healthy men and women. J Nutr 2011;141(5):964-970. doi:10.3945/jn.110.132985.

[49] Iwami D, Nonomura K, Shirasugi N, Niimi M. Immunomodulatory effects of eicosapentaenoic acid through induction of regulatory $\mathrm{T}$ cells. Int Immunopharmacol 2011;11(3):384-389. doi:10.1016/j.intimp.2010.11.035.

[50] Totzeck A, Stettner M, Hagenacker T. Early platelet and leukocyte decline in patients with neuroinflammatory disorders after intravenous immunoglobulins. Eur J Neurol 2017;24(4):638-644. doi:10.1111/ ene.13264.

[51] Gopaluni S, Jayne D. Clinical trials in vasculitis. Curr Treatm Opt Rheumatol 2016;2(2):161-177. doi:10.1007/s40674-016-0045-8.

[52] Saydain G, George L, Raoof S. New therapies: plasmapheresis, intravenous immunoglobulin, and monoclonal antibodies. Crit Care Clin 2002;18(4):957-975. doi:10.1016/S0749-0704(02)00028-3.

[53] Hoffmann JHO, Enk AH. High-dose intravenous immunoglobulins for the treatment of dermatological autoimmune diseases. J Dtsch Dermatol Ges 2017;15(12):1211-1226. doi:10.1111/ddg.13389.

[54] Leone VA, Cham CM, Chang EB. Diet, gut microbes, and genetics in immune function: can we leverage our current knowledge to achieve better outcomes in inflammatory bowel diseases? Curr Opin Immunol 2014;31:16-23. doi:10.1016/j.coi.2014.08.004.

[55] Habtezion A, Nguyen LP, Hadeiba H, Butcher EC. Leukocyte trafficking to the small intestine and colon. Gastroenterology 2016;150(2):340354. doi:10.1053/j.gastro.2015.10.046.

[56] Reifen R, Karlinsky A, Stark AH, Berkovich Z, Nyska A. $\alpha$-Linolenic acid (ALA) is an anti-inflammatory agent in inflammatory bowel disease. J Nutr Biochem 2015;26(12):1632-1640. doi:10.1016/j.jnutbio.2015.08.006

[57] Shaheen SO, Jameson KA, Syddall HE, Aihie Sayer A, Dennison EM, Cooper C, et al. The relationship of dietary patterns with adult lung function and COPD. Eur Respir J 2010;36(2):277-84. doi:10.1183/09031936.00114709.

[58] Bakker GC, van Erk MJ, Pellis L, Wopereis S, Rubingh CM, Cnubben $\mathrm{NH}$, et al. An antiinflammatory dietary mix modulates inflammation and oxidative and metabolic stress in overweight men: a nutrigenomics approach. Am J Clin Nutr 2010;91(4):1044-1059. doi:10.3945/ ajcn.2009.28822.

[59] Calder PC. Session 3: Joint Nutrition Society and Irish Nutrition and Dietetic Institute Symposium on 'Nutrition and autoimmune disease' PUFA, inflammatory processes and rheumatoid arthritis. Proc Nutr Soc 2008;67(4):409-418. doi:10.1017/S0029665108008690.

[60] Ramaswami R, Serhan CN, Levy BD, Makrides M. Fish oil supplementation in pregnancy. N Engl J Med 2016;375(26):2599-2601. doi:10.1056/NEJMclde1614333.

[61] Cacabelos R, Fernández-Novoa L, Corzo L, Pichel V, Lombardi V, Kubota Y. Genomics and phenotypic profiles in dementia: implications for pharmacological treatment. Methods Find Exp Clin Pharmacol 2004;26(6):421-444.

[62] Elena MO, Chandra R, Mangion T, Moniz C. Genomic and metabolomic patterns segregate with responses to calcium and vitamin D supplementation. Br J Nutr 2011;105(1):71-79. doi:10.1017/ S0007114510003065. 